\title{
Review Article \\ The Value of Peer Learning in Undergraduate Nursing Education: A Systematic Review
}

\author{
Robyn Stone, Simon Cooper, and Robyn Cant \\ Monash University, School of Nursing and Midwifery, Berwick Campus, 100 Clyde Road, Berwick 3806, Australia \\ Correspondence should be addressed to Robyn Stone; rwstol@student.monash.edu
}

Received 23 December 2012; Accepted 9 February 2013

Academic Editors: L. H. Beebe and M. M. Funnell

Copyright (C) 2013 Robyn Stone et al. This is an open access article distributed under the Creative Commons Attribution License, which permits unrestricted use, distribution, and reproduction in any medium, provided the original work is properly cited.

\begin{abstract}
The study examined various methods of peer learning and their effectiveness in undergraduate nursing education. Using a specifically developed search strategy, healthcare databases were systematically searched for peer-reviewed articles, with studies involving peer learning and students in undergraduate general nursing courses (in both clinical and theoretical settings) being included. The studies were published in English between 2001 and 2010. Both study selection and quality analysis were undertaken independently by two researchers using published guidelines and data was thematically analyzed to answer the research questions. Eighteen studies comprising various research methods were included. The variety of terms used for peer learning and variations between study designs and assessment measures affected the reliability of the study. The outcome measures showing improvement in either an objective effect or subjective assessment were considered a positive result with sixteen studies demonstrating positive aspects to peer learning including increased confidence, competence, and a decrease in anxiety. We conclude that peer learning is a rapidly developing aspect of nursing education which has been shown to develop students' skills in communication, critical thinking, and self-confidence. Peer learning was shown to be as effective as the conventional classroom lecture method in teaching undergraduate nursing students.
\end{abstract}

\section{Introduction}

Nursing education studies have often focused on traditional teaching methods such as classroom lecture learning, a behaviourism-based teaching method based on passive learning [1]. More effective student-centric learning methods are now being utilized to encourage active student participation and creative thinking [2-4]. One of these methods is peer learning, in which peers learn from one another, involving active student participation and where the student takes responsibility for their learning. Despite being used for many years, one of the barriers to advancement of peer learning is a lack of consistency in its definition [5]. It is known by different interchangeable titles such as "cooperative learning," "mentoring," "peer review learning," "peer coaching," "peer mentoring," "problem-based learning," and "team learning."

Peer learning has been used in education to address critical thinking, psychomotor skills, cognitive development, clinical skills, and academic gains [6-9]. One type of peer learning is problem-based learning (PBL) which is characterized by students learning from each other and from independently sourced information [10]. It is student centered, utilizing group work with the analysis of case studies as a means of learning. Alternatively "peer tutoring" involves individuals from similar settings helping others to learn, which may occur one-on-one or as small group sessions [11]. In nursing, high student numbers increase pressures [12] whilst varied and innovative teaching methods are beneficial [13] with peer learning offering a strategy that may be advantageous.

The Oxford Dictionary (2009) defines a "peer" as someone of the same age or someone who was attending the same university. The term "peer" can also refer to people who have equivalent skills or a commonality of experiences [14]. Both these definitions suit the concept of peer learning described here. The current study aimed to address the following research questions: (i) do undergraduate nursing students benefit from peer learning? and (ii) what approaches to peer learning are the most effective? 


\section{Methods}

Operational terms as shown in Table 1 were developed after consulting several studies. Inclusion and exclusion criteria were defined. A search was conducted for peer-reviewed papers published in English between the years 2000 and 2010 that discussed any aspect of the curriculum for undergraduate or general nursing courses (e.g., clinical skills, communication, patient interaction, or theoretical knowledge).

The literature search was undertaken using the PICO algorithm of Participant, Intervention, Comparison, and Outcome and guidelines from The Cochrane Handbook [15]. For this study the following terms were used:

$$
\begin{aligned}
& \text { participant-undergraduate nursing students, } \\
& \text { intervention-peer learning, } \\
& \text { comparison-classroom lecture learning, }
\end{aligned}
$$

outcome-improvement in theory results or results of practical assessment or personal feelings relating to comfort, confidence, or competence.

A systematic literature search of multiple databases and search engines was undertaken using the keywords and the search strategy described in the following. The keywords used were student nurse, undergraduate nurse, peer learning, peer tutoring, peer mentoring, education, and opinion leaders. Also used were variations and truncations of these words, for example, peer education, nurse education, and problembased learning. Each of the key words was searched for individually and then in combination with all others.

In addition, a number of key nursing journals such as Journal of Advanced Nursing and Journal of Nursing Education were hand-searched between the years 2000 and 2010. Snowballing, identifying suitable articles from the references of the selected studies, was then conducted to locate further studies.

Studies with all levels of evidence that met the criteria were included because studies in peer learning tended towards quasiexperimental, observational, or case study designs which are all lower on the hierarchy of evidence [16].

Two reviewers conducted a quality analysis of each study using quality criteria for qualitative and quantitative studies of the Critical Skills Appraisal Programme (CASP) [17]. They assessed methodology, validity, sample type, selection method, level of evidence, and any attrition rate and its effect (including biases), to determine selection. Consensus was reached through discussion. Data extraction and thematic analysis were undertaken to synthesize the data. Metaanalysis was not undertaken due to the inconsistent definition of "peer" and potential for bias if different methods of peer learning were combined. Although the primary review was conducted by a single researcher, inclusion and exclusion criteria were adhered to, using a transparent reporting process to allow the search to be reproduced.

Data were extracted and summarized in separate tables: quantitative studies (Table 2), qualitative studies (Table 3), and mixed method studies (Table 4). Drawing from this,

\begin{tabular}{|c|c|}
\hline Term & Definition \\
\hline Peer & $\begin{array}{l}\text { A person with a comparable or slightly higher } \\
\text { level of knowledge and experience to the learner. } \\
\text { A person of any age can be a peer, that is, a third } \\
\text { year student tutoring a first year student but the } \\
\text { peer must be an undergraduate nursing student. }\end{array}$ \\
\hline Peer learning & $\begin{array}{l}\text { Gaining, refining, or improving knowledge from } \\
\text { interaction with a peer as defined previously. }\end{array}$ \\
\hline Mentor & $\begin{array}{l}\text { A peer, who supports, guides, and educates a } \\
\text { learner. }\end{array}$ \\
\hline $\begin{array}{l}\text { Undergraduate } \\
\text { nursing student }\end{array}$ & $\begin{array}{l}\text { A nursing student at any stage of study prior to } \\
\text { registration. }\end{array}$ \\
\hline
\end{tabular}
data outcomes were collated into themes and subthemes; for
TABLE 1: Operational definitions.

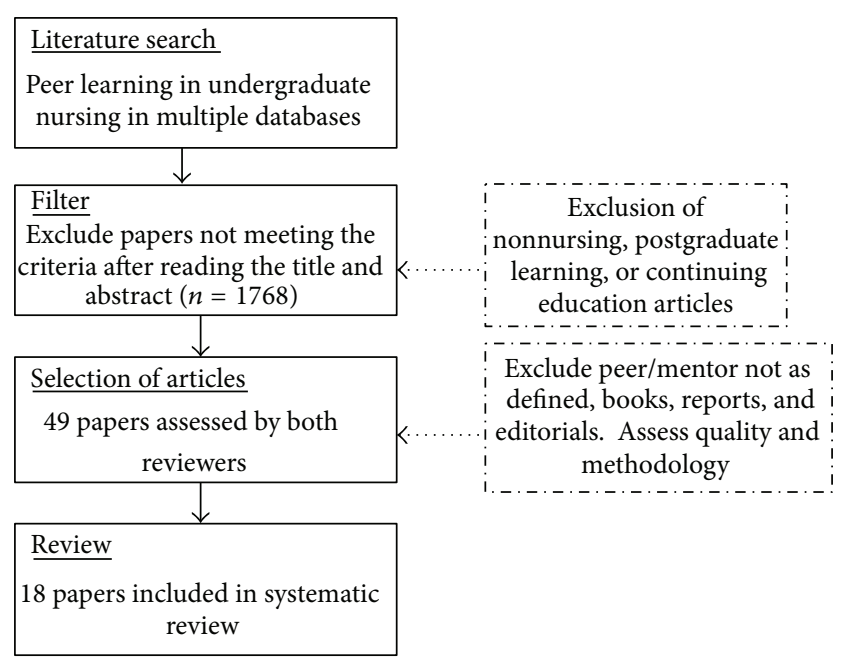

FIGURE 1: Flow chart of the systematic review selection process.

example, the resources theme had three subthemes: faculty, students, and peers.

\section{Results}

Initially, 1813 studies were screened using the aforementioned criteria and 18 studies were selected for review. A flow chart (Figure 1) shows the selection process including number of studies excluded at each stage and the reason for exclusion.

3.1. Characteristics of Studies. Participants were undergraduate nursing students from first to final year. In line with nursing demography the majority of participants were females. Participant numbers and study duration varied, for example, 15 students over a three-year period [18] and 365 students over a two-year period [7]. A variety of peer learning terms and methods were used. These terms included "peer mentoring" [19], "peer tutoring" [7, 20-23], "peer coaching” [24], "inquiry-based learning" $[25,26]$, "problem-based learning" [27-31], and "team learning" [32].

Of these studies, eight used a qualitative method, six utilized a quantitative method, and four used mixed methods 
TABLE 2: Summary of included studies.

\begin{tabular}{|c|c|c|c|}
\hline Author & Design & $\begin{array}{l}\text { Intervention and } \\
\text { comparison }\end{array}$ & Country and setting \\
\hline $\begin{array}{l}\text { Broscious and Saunders } \\
\text { (2001) [24] }\end{array}$ & $\begin{array}{c}\text { Mixed method } \\
\text { Group interview and questionnaire }\end{array}$ & Peer coaching & $\begin{array}{l}\text { Junior and senior year students: Christopher } \\
\text { Newport University in USA }\end{array}$ \\
\hline $\begin{array}{l}\text { Christiansen and Bell } \\
(2010) \text { [19] }\end{array}$ & $\begin{array}{l}\text { Qualitative } \\
\text { Interpretive }\end{array}$ & Peer learning & $\begin{array}{l}\text { UK University preregistration nursing } \\
\text { course }\end{array}$ \\
\hline $\begin{array}{l}\text { Christiansen and Jensen } \\
\text { (2008) [33] }\end{array}$ & $\begin{array}{l}\text { Qualitative } \\
\text { Ethnographic }\end{array}$ & Role playing & Third year student nurses in Norway \\
\hline $\begin{array}{l}\text { Cooke and Moyle (2002) } \\
\text { [27] }\end{array}$ & Qualitative_case studies & PBL versus CLL & $\begin{array}{l}\text { Second year students at university in } \\
\text { Australia }\end{array}$ \\
\hline Daley et al. (2008) [20] & $\begin{array}{l}\text { Qualitative } \\
\text { Observation, focus groups, and } \\
\text { journaling }\end{array}$ & Peer tutoring & $\begin{array}{l}\text { Ohio State University, College of Nursing } \\
\text { Students }\end{array}$ \\
\hline $\begin{array}{l}\text { Feingold et al. (2008) } \\
{[32]}\end{array}$ & $\begin{array}{l}\text { Mixed methods } \\
\text { Observation and interviews }\end{array}$ & Team learning & $\begin{array}{l}\text { First year student nurses: university in South } \\
\text { Western USA }\end{array}$ \\
\hline $\begin{array}{l}\text { Goldsmith et al. (2006) } \\
\text { [7] }\end{array}$ & $\begin{array}{l}\text { Mixed method } \\
\text { Portfolios, clinical assessment, and } \\
\text { questionnaires }\end{array}$ & Peer learning & $\begin{array}{l}\text { First/third year students: Clinical Practice } \\
\text { Unit (CPU) of a nursing school in Australia }\end{array}$ \\
\hline Higgins (2004) [21] & $\begin{array}{c}\text { Quantitative } \\
\text { Quasiexperimental }\end{array}$ & $\begin{array}{l}\text { Peer tutoring versus } \\
\text { nonpeer tutored }\end{array}$ & $\begin{array}{l}\text { Medical-surgical undergraduate nursing } \\
\text { course: Texas, USA }\end{array}$ \\
\hline Hughes et al. (2003) [35] & $\begin{array}{l}\text { Quantitative } \\
\text { Pretest/posttest crossover }\end{array}$ & $\begin{array}{l}\text { Peer group experience } \\
\text { versus nonpeer group } \\
\text { experience }\end{array}$ & Baccalaureate school of nursing in USA \\
\hline Horne et al. (2007) [25] & $\begin{array}{l}\text { Qualitative } \\
\text { Focus group interviews and use of } \\
\text { fourth generation evaluation }\end{array}$ & Enquiry-based learning & $\begin{array}{l}\text { Second year students at a higher education } \\
\text { setting in the UK }\end{array}$ \\
\hline Lin et al. (2010) [22] & $\begin{array}{l}\text { Quantitative } \\
\text { Experimental }\end{array}$ & $\begin{array}{l}\text { Peer tutoring. PBL method } \\
\text { in class versus CLL }\end{array}$ & Nursing ethics classes: university in Taiwan \\
\hline $\begin{array}{l}\text { Loke and Chow (2007) } \\
\text { [23] }\end{array}$ & $\begin{array}{l}\text { Qualitative } \\
\text { Focus groups and individual } \\
\text { interviews }\end{array}$ & Cooperative learning & $\begin{array}{l}\text { Second/third year student nurses: university } \\
\text { in Hong Kong }\end{array}$ \\
\hline $\begin{array}{l}\text { Morris and Turnbull } \\
\text { (2004) [26] }\end{array}$ & $\begin{array}{l}\text { Qualitative evaluation } \\
\text { Focus group interviews, field notes }\end{array}$ & Peer tutoring & $\begin{array}{l}\text { 3-year undergraduate nursing course in the } \\
\text { UK }\end{array}$ \\
\hline Ozturk et al. (2008) [28] & $\begin{array}{c}\text { Qualitative } \\
\text { Descriptive, analytical }\end{array}$ & PBL versus CLL & $\begin{array}{l}\text { Fourth year undergraduate student nurses } \\
\text { from two universities in Izmir, Turkey }\end{array}$ \\
\hline Rideout et al. (2002) [29] & $\begin{array}{l}\text { Quantitative survey } \\
\text { Cross-sectional analytical design }\end{array}$ & PBL versus CLL & $\begin{array}{l}\text { Baccalaureate school of nursing and CLL } \\
\text { programme in Canada }\end{array}$ \\
\hline Roberts (2008) [18] & $\begin{array}{l}\text { Qualitative } \\
\text { Interpretive ethnographic }\end{array}$ & Informal peer learning & $\begin{array}{l}\text { Undergraduate students over a three-year } \\
\text { course in a range of acute settings including } \\
\text { intensive care, general surgical, } \\
\text { rehabilitation, and medical wards in the UK }\end{array}$ \\
\hline Siu et al. (2005) [30] & $\begin{array}{c}\text { Quantitative } \\
\text { Descriptive, correlation survey } \\
\text { design }\end{array}$ & PBL versus CLL & Two universities in Ontario, Canada \\
\hline Tiwari et al. (2006) [31] & $\begin{array}{l}\text { Mixed methods } \\
\text { Random controlled trial and survey }\end{array}$ & PBL versus CLL & $\begin{array}{l}\text { First year student nurses: university in Hong } \\
\text { Kong }\end{array}$ \\
\hline
\end{tabular}

PBL: problem-based learning, CLL: classroom lecture learning.

(see Table 2). The quantitative studies favoured scaling and rating approaches (e.g., Likert scales), applying valid tools including the Californian Critical Thinking Disposition Inventory [28, 31], the Psychological Empowerment Scale [30], or the Nursing Ethical Discrimination Ability Scale [22] to collect data. The qualitative studies used a variety of collection methods such as participant observation [18], focus groups [19, 20, 25, 26, 33], individual interviews [23], and open ended short answer questions [27]. Combinations of these methods were used by the mixed method studies. In addition a variety of statistics software and applicable inferential statistics were used in the quantitative and mixed method studies, whilst the qualitative studies used applicable thematic approaches to analysis.

The analysis tools and tests used were presented (see Tables 1, 2, 3, 4, and 5) and considered as part of the quality analysis. Whilst quantitative studies give a definitive, measurable result, the use of qualitative studies in this paper 


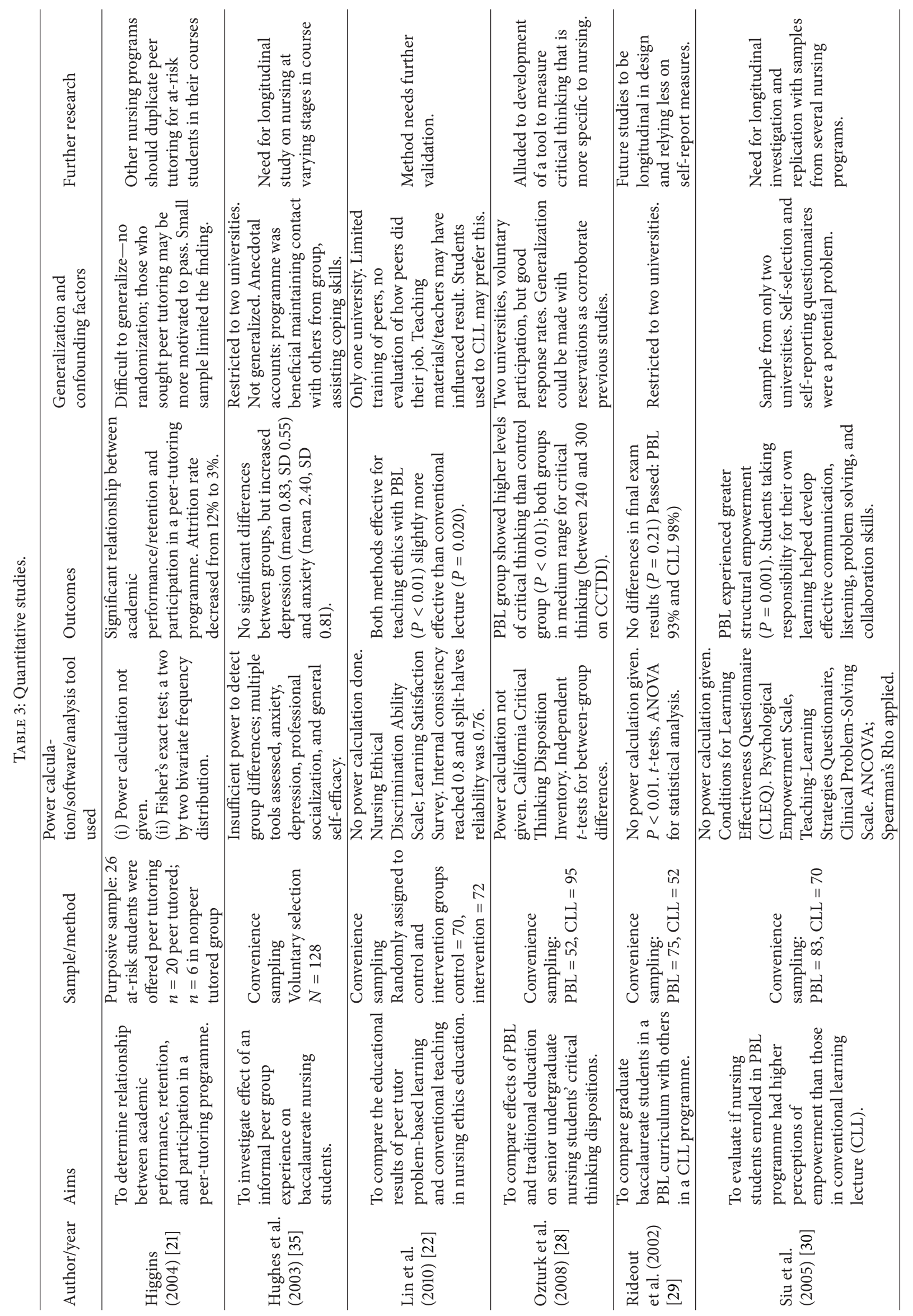




\begin{tabular}{|c|c|c|c|c|c|c|c|c|}
\hline & 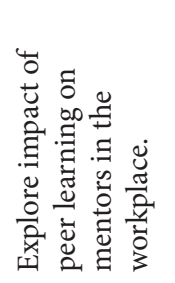 & 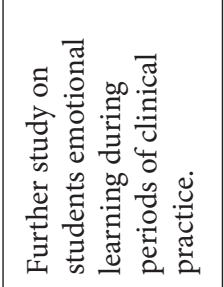 & 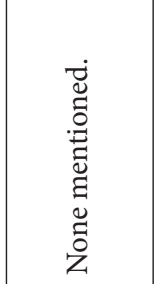 & 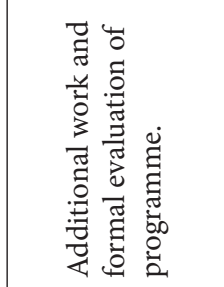 & 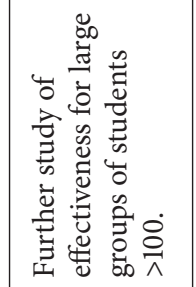 & 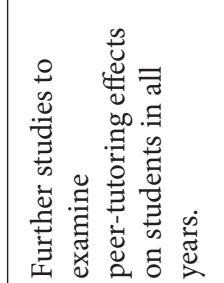 & 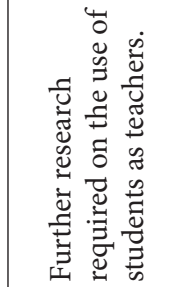 & 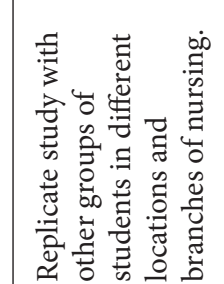 \\
\hline & 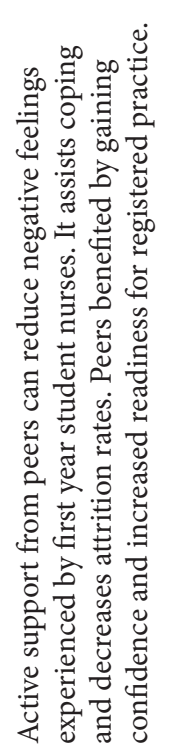 & 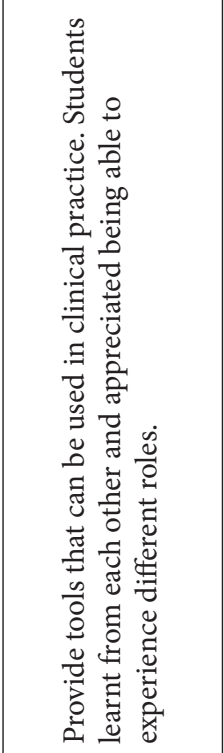 & 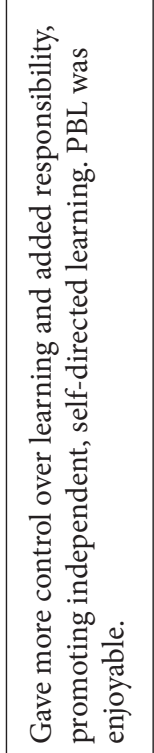 & 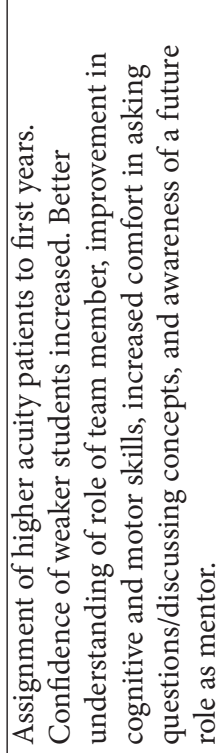 & 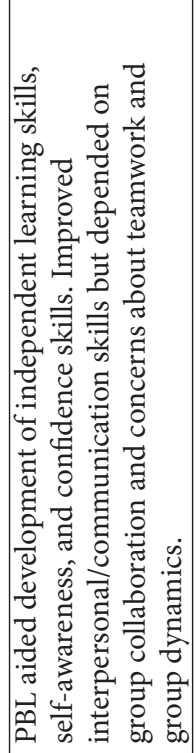 & 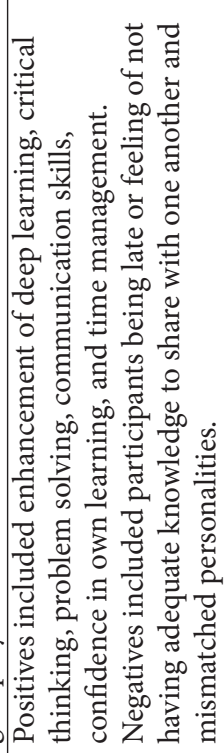 & 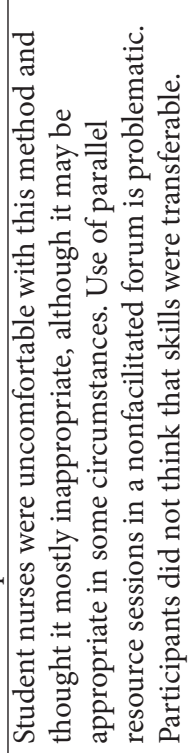 & 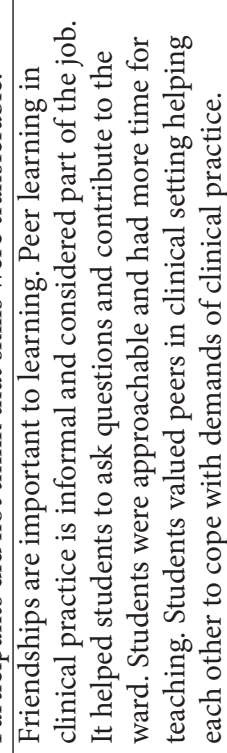 \\
\hline & 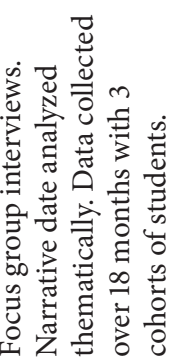 & 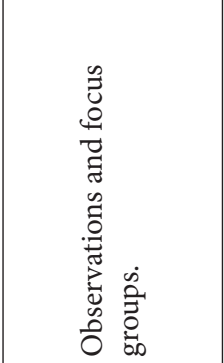 & 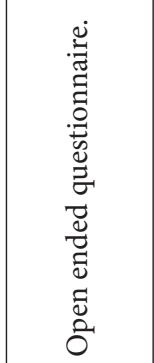 & 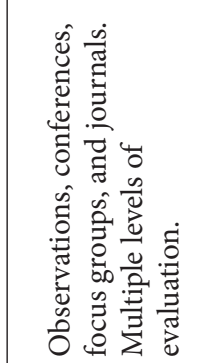 & 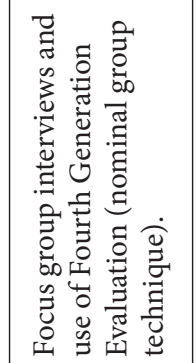 & 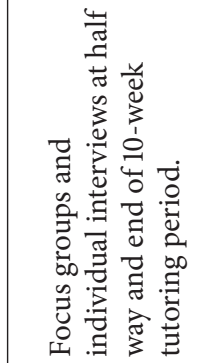 & 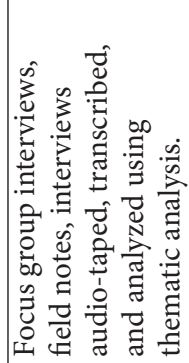 & 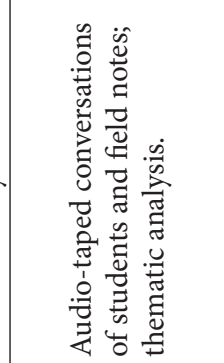 \\
\hline & 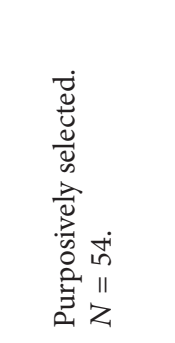 & 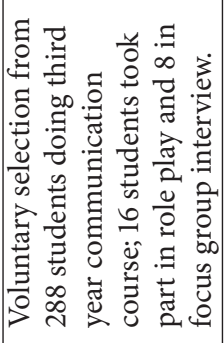 & 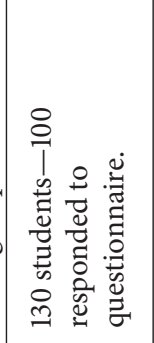 & 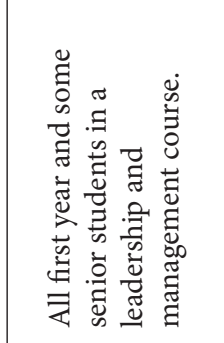 & 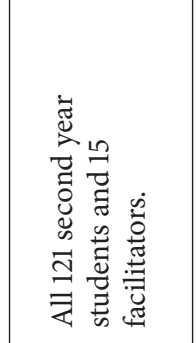 & 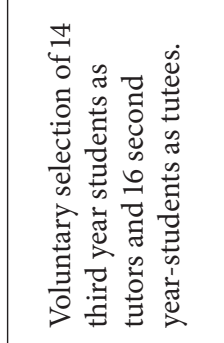 & 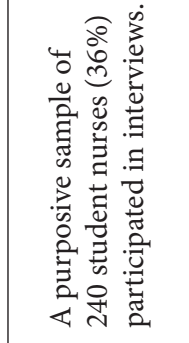 & 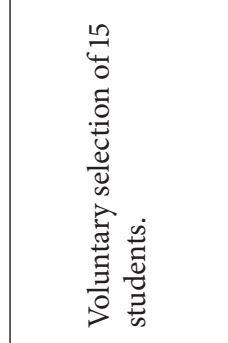 \\
\hline & 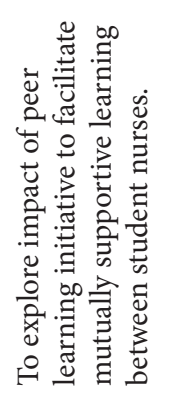 & 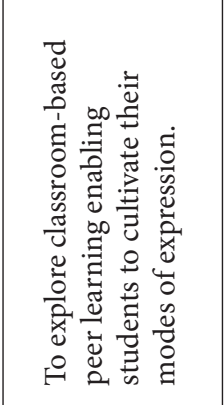 & 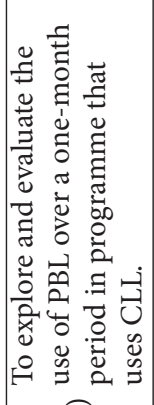 & 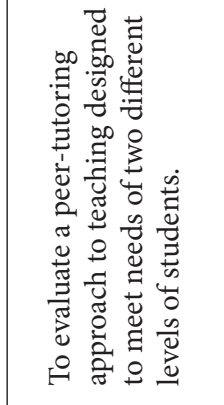 & 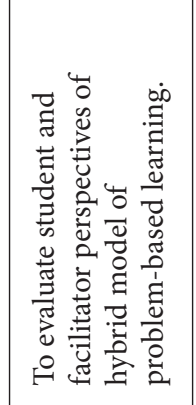 & 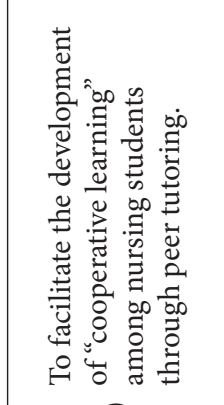 & 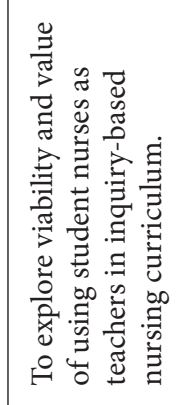 & 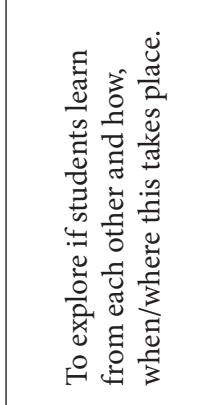 \\
\hline & 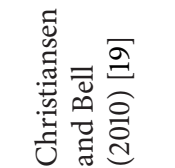 & 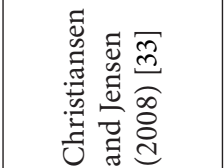 & 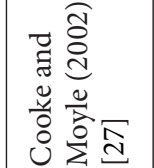 & 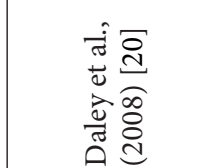 & : & 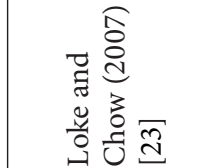 & 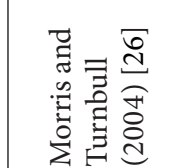 & $\frac{2}{3}$ \\
\hline
\end{tabular}




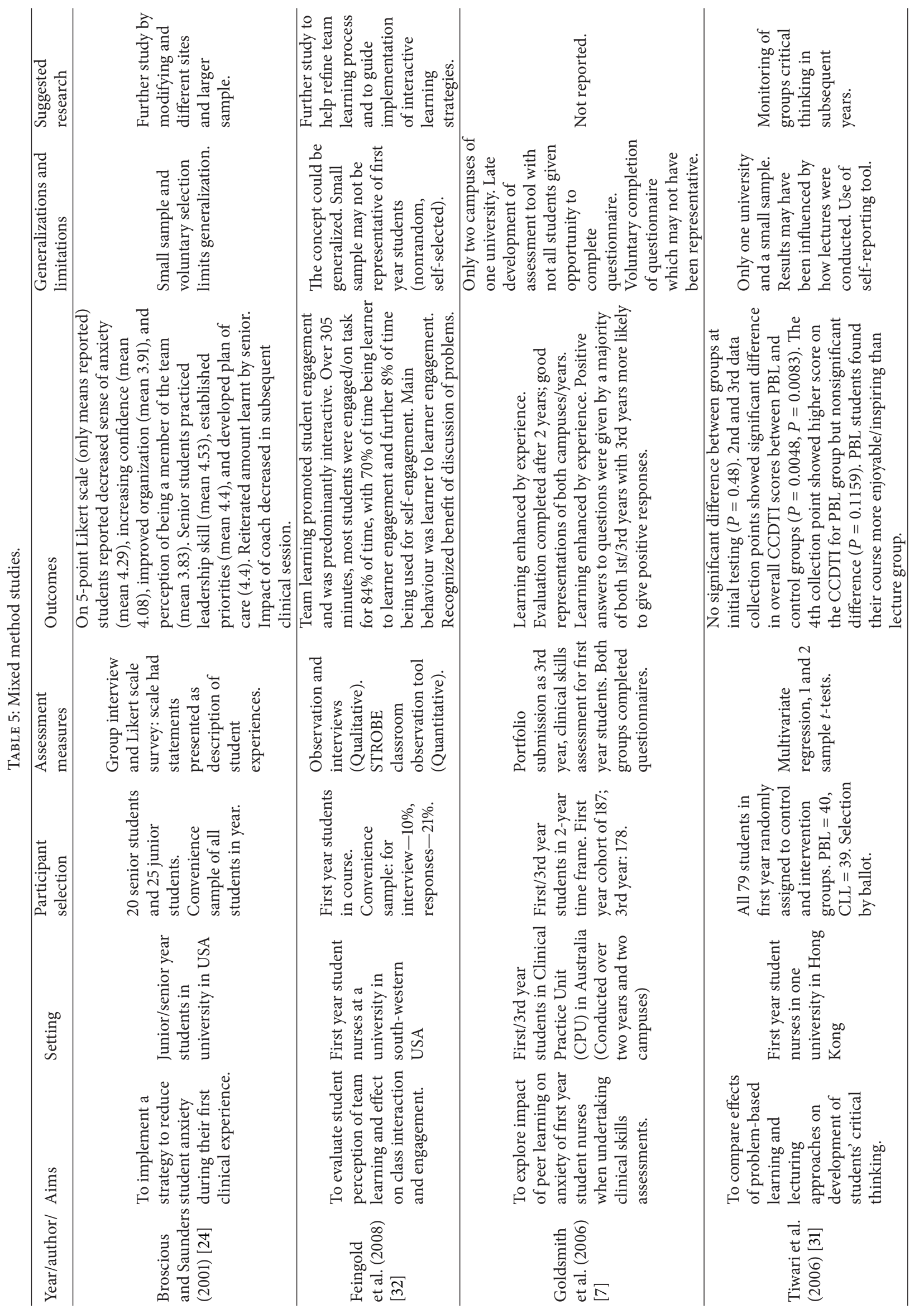


examined how the participants felt about a different method of learning and how it impacted on them. These opinions would be important if peer learning was to gain acceptance from the students and peers. Qualitative studies had much smaller participant numbers and whilst larger numbers may have provided a more comprehensive sample, there were saturation and repetition of concepts even with the smaller samples.

Experimental studies with the highest level of evidence, that is, random controlled trials (RCTs), were not a common method of evaluating peer learning as they may not reproduce the true situation in an educational setting [34].

Eight studies used a comparison group [21, 22, 27-31, 35], and all except two $[27,31]$ were quantitative studies. Valid tools were used by 9 of the 10 quantitative or mixed method studies. It was concluded that valid tools measured what the authors intended, and hence data were an accurate representation of what had occurred and were credible. However, one study [21] failed to report the number of control and intervention group participants who passed their course. The qualitative studies documented the research process clearly, and the findings were consistent with the data provided. The details in description of the research process and findings varied between studies, whilst within individual studies, sample size, location, and the subjects taught were all potentially limiting; for example, small sample size, specific location, or subject may have caused a bias in the results, hence affecting the transferability of results $[24,31]$. Publication bias was not evident as the included studies reported both the positive and negative results, for example, using comments from participants [26] or differences in means [35].

3.2. Effects of Peer Learning. Peer learning encouraged independent study, critical thinking, and problem solving skills. It could give students a sense of autonomy when they accepted responsibility for their own education. Peer learning was associated with increased levels of knowledge in a number of areas such as problem solving and communication [20, 25]. Tiwari et al. [31] showed that critical thinking was improved in students using PBL $(P=0.0048)$ whilst Daley et al. [20] reported that students showed improvement in cognitive and motor skills. An advantage of peer learning was that both groups learned and benefited from the interaction [23, 24]. The benefits differed between the students and peers with the peers gaining experience in communication and leadership, reinforcing their prior learning and discovering what they were capable of achieving in the mentoring/teaching fields $[19,24]$. On the other hand, students gained confidence and experienced a decrease in anxiety when dealing with certain situations such as clinical placements. PBL was reported to be effective particularly in the theoretical learning component of education whilst peer tutoring, peer coaching, peer mentoring, and the use of role play as a form of peer learning were all effective, both in clinical and theoretical aspects of nursing education.

One negative aspect was related to anxiety levels. Group learning showed an increase in anxiety in both control and intervention groups [35], whilst other methods such as peer coaching showed a decrease in anxiety in the clinical setting [24]. The students indicated that having another person assist them decreased their anxiety levels which was pertinent when they were beginning their careers and were uncertain and anxious about what was expected of them [18]. Informal peer learning also benefited the students by providing them with "survival" skills that are not taught in lectures or text books, which in turn assisted in decreasing anxiety [18].

In addition to decreasing anxiety [24], many students showed an increase in satisfaction when peer learning was used $[22,29]$, appreciating having to think for themselves, problem-solve, and work as a team [20,24, 27, 30]. The level of satisfaction is higher with peer learning [29] than the passive CLL method although some students still prefer CLL as it maybe better suited their individual learning style [22]. Whilst none of the studies in this paper directly investigated the link between course satisfaction and academic results, Higgins [21] noted a decrease in attrition rate but did not specify student satisfaction levels.

Four studies [20,23-25] examined confidence in students when utilizing peer learning. They showed a subjective increase in confidence levels when completing clinical skills, problem solving, and critical thinking. In addition, 11 studies indicated that students appreciated interactive learning sessions and the emphasis on active participation, which encouraged them to take ownership and responsibility for their own learning.

3.3. Utilization. Peer learning was utilized in multiple situations from teaching ethics [22] and critical thinking [31] to helping students deal with emotional situations [19] with patients. In clinical situations peer learning was successful and improved integration into the ward situations [18] and students' confidence when dealing with actual patients rather than a simulator [20]. Further, a number of studies identified outcome measures showing an improvement in either an objective or subjective assessment.

\section{Discussion}

The purpose of this research was to ascertain whether undergraduate nursing students benefit from peer learning. Sixteen of eighteen studies demonstrated positive aspects to peer learning with outcome measures showing improvement in either an objective effect or a subjective assessment (such as a self-rated increase in student confidence). Furthermore, learning from peers was shown to be acceptable to most students. Much of the research into peer learning concentrated on formal peer learning with the evidence supporting the concept that peer learning may be an equally, if not more, effective method of delivering information in undergraduate nursing education.

Peer learning can be utilized to pass information to large groups of students with less faculty member involvement. At a time when there is pressure to train more nurses and minimize costs [12], peer learning could utilize resources more effectively with students teaching and supervising more 
junior students, thus decreasing the demand on the responsible faculty members. Therefore it may have cost benefits for managing some aspects of nursing education; however this theory requires further investigation as it was not the focus of any of the papers mentioned in this paper.

Regardless of any decrease in active involvement by lecturers, the need for student supervision remains important. If peers are not knowledgeable or do not have the appropriate skills, then they cannot accurately pass information onto another student. The learning of inaccurate information could potentially cause issues for students when these inaccuracies were demonstrated in exams and on clinical placements. Without supervision, learning may not be effective as shown in an earlier study by Parkin [4] who found that observation and supervision were required in all peer learning to ensure that correct and current information was being exchanged.

4.1. Advantages and Disadvantages. Peer learning may result in information being more readily accepted by a student as individuals often turn to others who have similar experiences, for advice and guidance. This could decrease anxiety associated with learning due to familiarity of the peer with the student's issues. As noted in the results, anxiety may occur when individuals are exposed to new concepts, whether they are novice or proficient learners [36]. In prior research [37], peer learning helped to decrease the student's anxiety and assisted them to fit into a ward situation and feel like part of the team. This sense of belonging has social implications particularly when it is known that learning occurs more effectively when there is socialization $[38,39]$.

Further, social interaction and collaboration between peer and student may have contributed to an increased learning curve and acquisition of further knowledge than would have occurred if students were studying independently. This was illustrated in this paper with students who had been in danger of failing and had received peer tutoring [21]. They gained additional knowledge and improved their academic result. This method may also allow junior students to problem-solve issues with their patients more independently and care for higher acuity patients, leading to an increase in their self-confidence. This concept was previously reported by Vygotsky [40], Aston and Molassiotis [41], and Secomb [5] who found that peer learning promoted self-confidence in junior students whilst assisting senior students with mentoring and teaching skills. Secomb [5] also showed that peer learning was an effective learning tool in clinical situations with both nursing and other health professionals. Peers perceived an increase in patient care competence when peer learning was utilized. Secomb [5] noted, however, that issues such as inappropriate pairing of students and peers should be addressed prior to the intervention.

Student satisfaction may play a part in scholastic achievement through acceptance of an active learning method such as peer learning. Four studies investigating this component $[22,28-30]$ discovered that students were satisfied with peer learning as the educational method. This may be because the student takes more responsibility and actively participates in their education, giving them a sense of autonomy. Whilst Ozturk et al. [28] reported a higher satisfaction level with PBL but no significant difference in academic scores, previous studies have shown a positive association between student satisfaction and grades achieved $[42,43]$.

Peer learning may also be more successful when peers are close in experience or stage of training as it provides a more relaxed, less intimidating, more "user friendly" learning experience than sessions conducted by registered nurses. Prior to the current study, El Ansari and Oskrochi [44], Eisen [45], and Secomb [5] also reported this finding whilst more recently Bensfield et al. [46] reported that first year students had comfortable learning with more experienced peers.

There is, however, a different perspective. Whilst peer learning has been used for years and might be becoming the norm, students may not be fully familiar with it and therefore be apprehensive about what it offers. Some students reported anxiety and apprehension when taking part in peer learning which was linked to feeling responsible for another's education $[25,26]$, being underprepared [23] or concerned that their own grades would be negatively affected by group work or dynamics $[25,26,32]$. Further, it was reported that enforcing the educational role of a peer may lead to resentment, particularly if the nurse felt unprepared or unwilling to undertake the role [26]. Previously Bensfield et al. [46] showed that whilst nurses have a responsibility to teach others, many are reluctant to do so as they feel unprepared for the role. Due to these issues, students who are familiar and comfortable with CLL may continue to prefer this learning method over peer learning.

4.2. Confusing Terminology Used in Peer Learning. Finally, this paper raises issues around the confusing terminology used to refer to peer learning. As mentioned, multiple terms such as peer teaching, peer mentoring, and peer coaching were used interchangeably with debate about whether they meant the same thing or referred to subtle differences in meaning. A clearer definition of each of the terms is needed to increase the rigor of nursing education research, as was also raised by Secomb [5], Eisen [45], and McKenna and French [47] who found a lack of clarity as to what peer education entailed due to the interchanging of terminology. We suggest amalgamation of some of the terms, for example, team learning and cooperative learning or peer mentoring and peer coaching and having distinct differences in definitions between other terms.

\section{Limitations}

Some limitations of this study were recognized. Only studies published in English were included. Despite a rigorous search strategy, some relevant articles may have been omitted owing to the search terms used. The mix of study designs and various methods of reporting meant that direct comparison between studies was limited. Some studies were location- or topic-specific, and some studies collected data using indirect outcome measures. However, the collection and review of the diverse papers that were selected offered the best option for 
determining the overall impact of peer learning in education of nursing students.

\section{Conclusion}

Peer learning: learning from others who possess a similar level of knowledge, is becoming a part of nursing education. This study showed that undergraduate nursing students could benefit from peer learning, with an increase in confidence and competence and a decrease in anxiety. Their peers also gained skills to prepare them for their role as a registered nurse. Conduct of peer learning within the curriculum was shown to require adequate academic supervision to be effective. It was difficult to ascertain the most effective learning methods because of the inherent variation between study methodologies, terminology, subjects, and settings. Inconsistency terminology was identified as a problem that should be addressed in order to provide clarity in future research.

\section{Further Research}

Further research is needed to fully investigate peer learning with the use of larger samples, various targeted curricula, courses, and locations to increase the validity of studies. The cost effectiveness of peer learning should be further investigated and compared to that of CLL to ascertain how this option could impact nursing education in terms of resources, time management, and effectiveness.

\section{References}

[1] C. L. Iwasiw, D. Goldenderg, and M. A. Andrusyszyn, Curriculum Development in Nursing Education, Jones \& Bartlett, Boston, Mass, USA, 2nd edition, 2009.

[2] M. Banning, "Approaches to teaching: current opinions and related research," Nurse Education Today, vol. 25, no. 7, pp. 502508, 2005.

[3] S. Paterson and R. Stone, "Educational leadership beyond behaviourism, the lessons we have learnt from art education," Australian Art Education, vol. 29, no. 1, pp. 76-83, 2006.

[4] V. Parkin, "Peer education: the nursing experience," Journal of Continuing Education in Nursing, vol. 37, no. 6, pp. 257-264, 2006.

[5] J. Secomb, "A systematic review of peer teaching and learning in clinical education," Journal of Clinical Nursing, vol. 17, no. 6, pp. 703-716, 2008.

[6] L. D. Owens and D. J. Walden, "Peer instruction in the learning laboratory: a strategy to decrease student anxiety," Journal of Nursing Education, vol. 40, no. 8, pp. 375-377, 2001.

[7] M. Goldsmith, L. Stewart, and L. Ferguson, "Peer learning partnership: an innovative strategy to enhance skill acquisition in nursing students," Nurse Education Today, vol. 26, no. 2, pp. 123-130, 2006.

[8] S. Blowers, P. Ramsey, C. Merriman, and J. Grooms, "Patterns of peer tutoring in nursing," Journal of Nursing Education, vol. 42, no. 5, pp. 204-211, 2003.

[9] H. Yuan, B. A. Williams, and L. Fan, "A systematic review of selected evidence on developing nursing students' critical thinking through problem-based learning," Nurse Education Today, vol. 28, no. 6, pp. 657-663, 2008.

[10] A. J. Neville, "Problem-based learning and medical education forty years on: a review of its effects on knowledge and clinical performance," Medical Principles and Practice, vol. 18, no. 1, pp. $1-9,2008$.

[11] D. Nestel and J. Kidd, "Peer tutoring in patient-centred interviewing skills: experience of a project for first-year students," Medical Teacher, vol. 25, no. 4, pp. 398-403, 2003.

[12] H. T. Allan, P. A. Smith, and M. Lorentzon, "Leadership for learning: a literature study of leadership for learning in clinical practice," Journal of Nursing Management, vol. 16, no. 5, pp. 545$555,2008$.

[13] D. Shipman and J. Hooten, "Without enough nurse educators there will be a continual decline in RNs and the quality of nursing care: contending with the faculty shortage," Nurse Education Today, vol. 28, no. 5, pp. 521-523, 2008.

[14] J. Green, "Peer education," Promotion \& Education, vol. 8, no. 2, pp. 65-68, 2001.

[15] J. P. T. Higgins and S. Green, "Cochrane Handbook for systematic reviews of interventions: The Cochrane Collaboration," 2009, http://www.cochrane-handbook.org/ .

[16] The National Health and Medical Research Council, NHMRC Additional Levels of Evidence and Grades for Recommendations for Developers of Guidelines. Stage 2 Consultation, The Australian Government, Parkes ACT, Australia, 2009.

[17] Public Health Resource Unit, "Critical Appraisal Skills Programme Making sense of evidence, 10 questions to help you make sense of reviews," 2006, http://www.phru.nhs.uk/ Doc_Links/S.Reviews\%20Appraisal\%20Tool.pdf.

[18] D. Roberts, "Learning in clinical practice: the importance of peers," Nursing Standard, vol. 23, no. 12, pp. 35-41, 2008.

[19] A. Christiansen and A. Bell, "Peer learning partnerships: exploring the experience of pre-registration nursing students," Journal of Clinical Nursing, vol. 19, no. 5-6, pp. 803-810, 2010.

[20] L. K. Daley, E. Menke, B. Kirkpatrick, and D. Sheets, "Partners in practice: a win-win model for clinical education," Journal of Nursing Education, vol. 47, no. 1, pp. 30-32, 2008.

[21] B. Higgins, "Relationship between retention and peer tutoring for at-risk students," Journal of Nursing Education, vol. 43, no. 7, pp. 319-321, 2004.

[22] C. F. Lin, M. S. Lu, C. C. Chung, and C. M. Yang, "A comparison of problem-based learning and conventional teaching in nursing ethics education," Nursing Ethics, vol. 17, no. 3, pp. 373-382, 2010.

[23] A. Y. Loke and F. L. W. Chow, "Learning partnership-the experience of peer tutoring among nursing students: a qualitative study," International Journal of Nursing Studies, vol. 44, no. 2, pp. 237-244, 2007.

[24] S. K. Broscious and D. J. Saunders, "Peer coaching," Nurse Educator, vol. 26, no. 5, pp. 212-214, 2001.

[25] M. Horne, K. Woodhead, L. Morgan, L. Smithies, D. Megson, and G. Lyte, "Using enquiry in learning: from vision to reality in higher education," Nurse Education Today, vol. 27, no. 2, pp. 103-112, 2007.

[26] D. Morris and P. Turnbull, "Using student nurses as teachers in inquiry-based learning," Journal of Advanced Nursing, vol. 45, no. 2, pp. 136-144, 2004.

[27] M. Cooke and K. Moyle, 'Students' evaluation of problembased learning," Nurse Education Today, vol. 22, no. 4, pp. 330$339,2002$. 
[28] C. Ozturk, G. K. Muslu, and A. Dicle, "A comparison of problem-based and traditional education on nursing students' critical thinking dispositions," Nurse Education Today, vol. 28, no. 5, pp. 627-632, 2008.

[29] E. Rideout, V. England-Oxford, B. Brown et al., "A comparison of problem-based and conventional curricula in nursing education," Advances in Health Sciences Education, vol. 7, no. 1, pp. 3-17, 2002.

[30] H. M. Siu, H. K. Spence Laschinger, and E. Vingilis, “The effect of problem-based learning on nursing students' perceptions of empowerment," Journal of Nursing Education, vol. 44, no. 10, pp. 459-469, 2005.

[31] A. Tiwari, P. Lai, M. So, and K. Yuen, "A comparison of the effects of problem-based learning and lecturing on the development of students' critical thinking," Medical Education, vol. 40, no. 6, pp. 547-554, 2006.

[32] C. E. Feingold, M. D. Cobb, R. Hernandez Givens, J. Arnold, S. Joslin, and J. L. Keller, "Student perceptions of team learning in nursing education," Journal of Nursing Education, vol. 47, no. 5, pp. 214-222, 2008.

[33] B. Christiansen and K. Jensen, "Emotional learning within the framework of nursing education," Nurse Education in Practice, vol. 8 , no. 5 , pp. 328-334, 2008.

[34] B. Jolly, "Control and validity in medical educational research," Medical Education, vol. 35, no. 10, pp. 920-921, 2001.

[35] L. C. Hughes, P. Romick, M. K. Sandor et al., "Evaluation of an informal peer group experience on baccalaureate nursing students' emotional well-being and professional socialization," Journal of Professional Nursing, vol. 19, no. 1, pp. 38-48, 2003.

[36] L. T. Adams, "Nursing shortage solutions and America's economic recovery," Nursing Education Perspectives, vol. 30, no. 6, p. 349, 2009.

[37] P. Benner, "Using the dreyfus model of skill acquisition to describe and interpret skill acquisition and clinical judgment in nursing practice and education," Bulletin of Science, Technology and Society, vol. 24, no. 3, pp. 188-199, 2004.

[38] J. M. Parr and M. A. R. Townsend, "Environments, processes, and mechanisms in peer learning," International Journal of Educational Research, vol. 37, no. 5, pp. 403-423, 2002.

[39] I. A. G. Wilkinson, "Peer influences on learning: where are they?" International Journal of Educational Research, vol. 37, no. 5, pp. 395-401, 2002.

[40] L. S. Vygotsky, Biological and Social Factors in Education. Educational Psychology, St. Lucie Press, Boca Raton, Fla, USA, 1997.

[41] L. Aston and A. Molassiotis, "Supervising and supporting student nurses in clinical placements: the peer support initiative," Nurse Education Today, vol. 23, no. 3, pp. 202-210, 2003.

[42] B. Sinclair and K. Ferguson, "Integrating simulated teaching/ learning strategies in undergraduate nursing education," International Journal of Nursing Education Scholarship, vol. 6, no. 1, p. 7, 2009.

[43] P. M. Casey, D. Magrane, and T. G. Lesnick, "Improved performance and student satisfaction after implementation of a problem-based preclinical obstetrics and gynecology curriculum," American Journal of Obstetrics and Gynecology, vol. 193, no. 5, pp. 1874-1878, 2005.

[44] W. El Ansari and R. Oskrochi, "What matters most? Predictors of student satisfaction in public health educational courses," Public Health, vol. 120, no. 5, pp. 462-473, 2006.

[45] M. J. Eisen, "Peer-based professional development viewed through the lens of transformative learning," Holistic Nursing Practice, vol. 16, no. 1, pp. 30-42, 2001.
[46] L. Bensfield, P. A. Solari-Twadell, and S. Sommer, "The use of peer leadership to teach fundamental nursing skills," Nurse Educator, vol. 33, no. 4, pp. 155-158, 2008.

[47] L. McKenna and J. French, "A step ahead: teaching undergraduate students to be peer teachers," Nurse Education in Practice, vol. 11, no. 2, pp. 141-145, 2011.

[48] D. Nestel and J. Kidd, "Peer assisted learning in patient-centred interviewing: the impact on student tutors," Medical Teacher, vol. 27, no. 5, pp. 439-444, 2005.

[49] R. Duggan, "A little help from your PALs," Nursing Standard, vol. 14 , no. 38 , p. 55, 2000.

[50] J. E. Duchscher, "Peer learning: a clinical teaching strategy to promote active learning," Nurse Educator, vol. 26, no. 2, pp. 5960, 2001.

[51] S. Dennison, "Peer mentoring: untapped potential," Journal of Nursing Education, vol. 49, no. 6, pp. 340-342, 2010. 


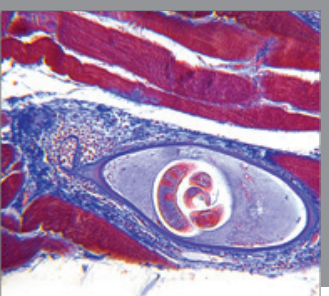

Gastroenterology

Research and Practice
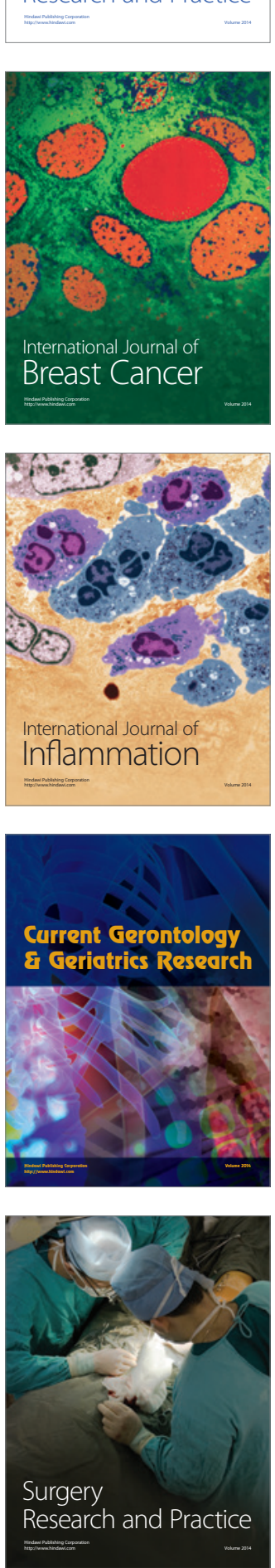

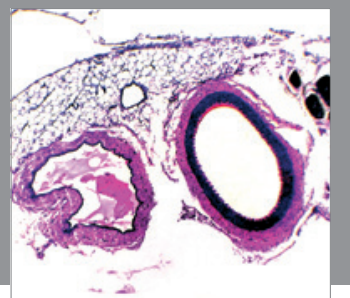

International Journal of Hypertension
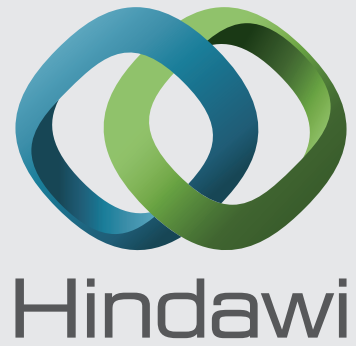

Submit your manuscripts at http://www.hindawi.com
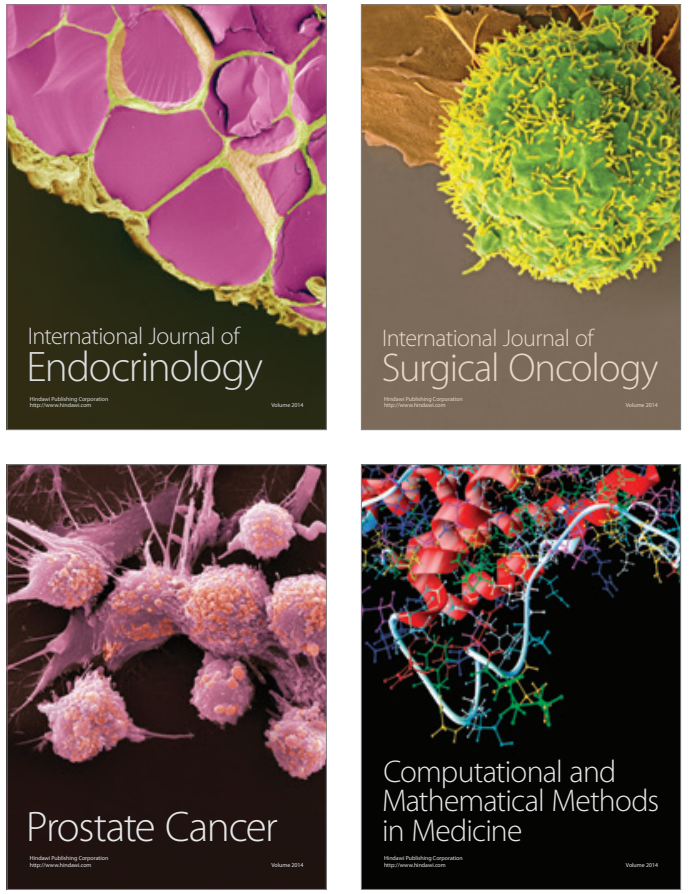
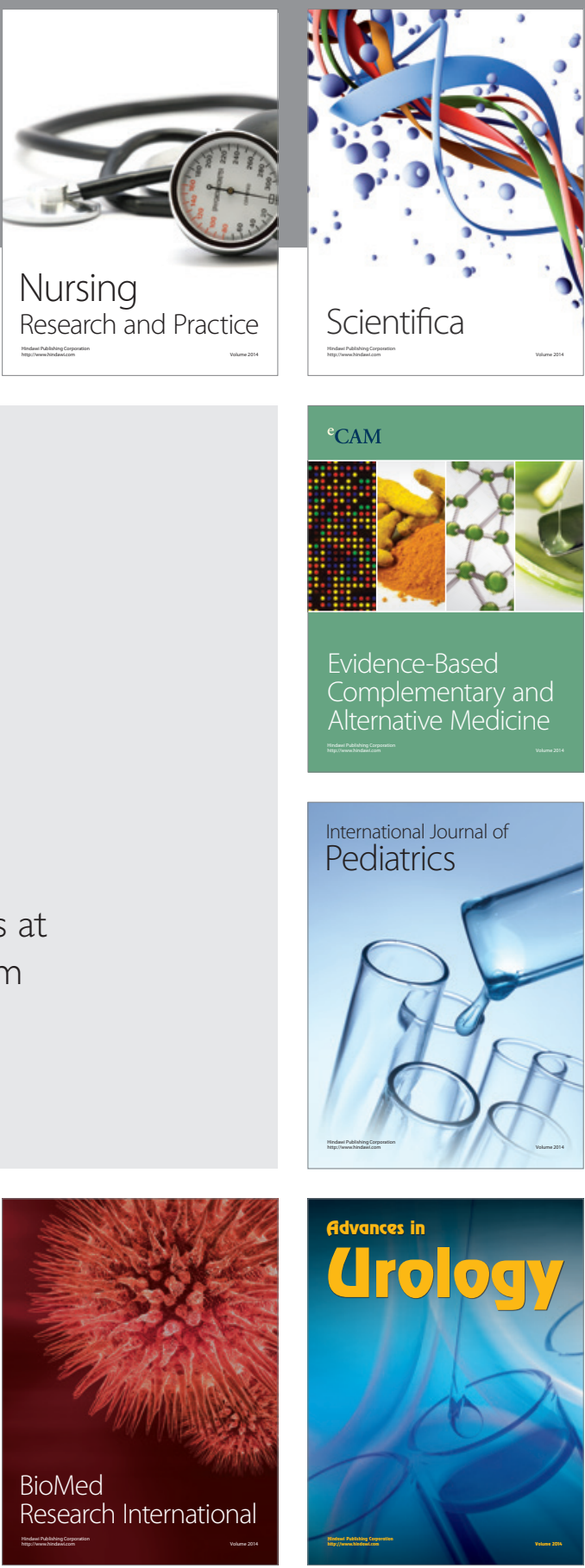

Nursing

Research and Practice

Scientifica

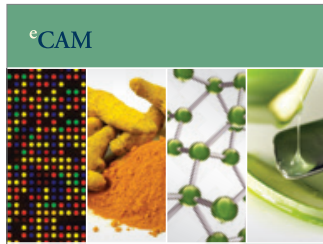

Evidence-Based

Complementary and Alternative Medicine
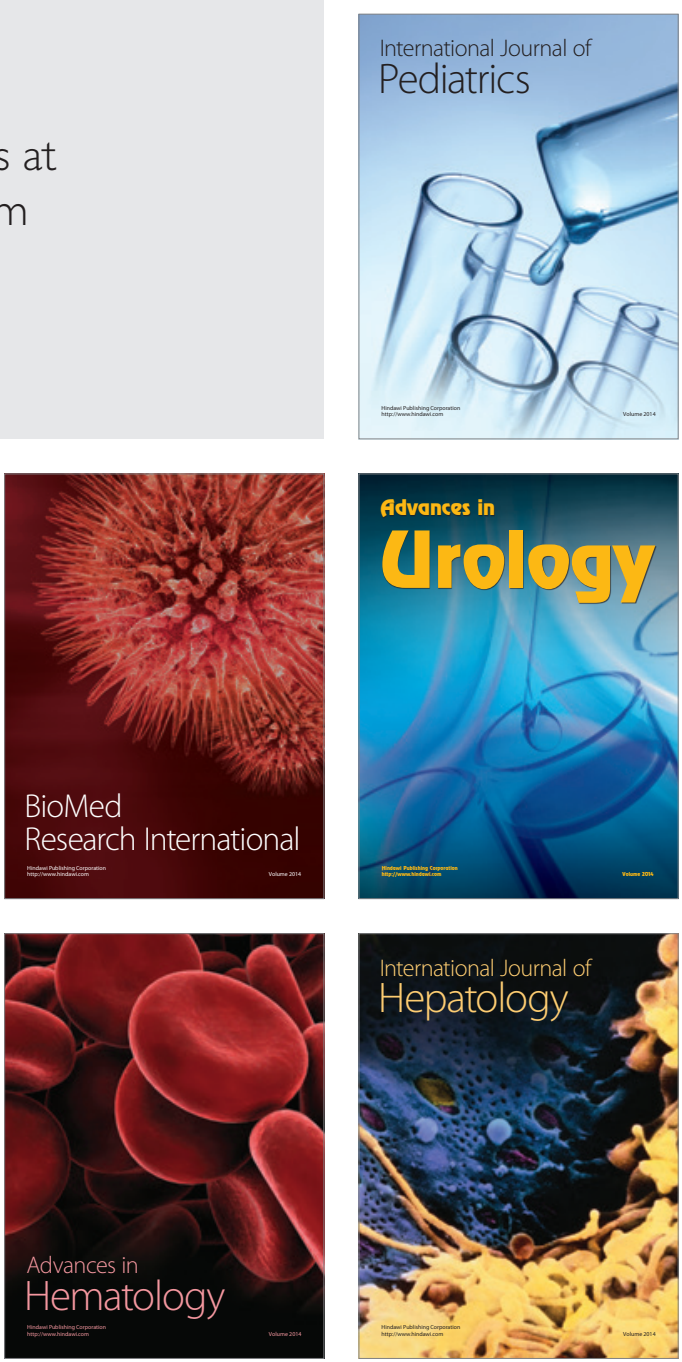